\title{
Price ceilings and firm-specific quantity restrictions in posted-offer markets
}

\author{
Praveen $\mathrm{Kujal}^{*}$
}

Universidad Carlos III de Madrid, Calle Madrid 126-128, 28903 Getafe, Madrid, Spain

\begin{abstract}
The effect of price ceilings and quantity controls in experimental posted-offer markets on market efficiency and total output is compared. Quantity controls adversely affect market performance relative to price ceilings. In the quota experiments contract and total surplus realization is lower than under equivalent price controls. Welfare outcomes, in terms of market efficiency, for price ceilings and quantity controls in a market setting are not the same, at least in the short run. Different welfare outcomes from equivalent controls are attributed to the manner in which the price and quantity search space is 'censored' by the price and quantity controls.
\end{abstract}

\section{Introduction}

Experimental methods have been used lately as a test-bed for studying auctions and the effect of changing market rules, or government policies, on market outcomes $^{1}$. The appeal of using experiments for such uses lies in the fact that they provide a cheap and simple alternative to directly testing policies in real markets. Further, new auction mechanisms, economic policies, or market rules, can be tested at a relatively low cost in a controlled environment where it is easier to isolate the effect of changing a single variable. Experimental methods have been applied for example to study, allocation of airport slots (Rassenti et al., 1982), gas and electricity networks (McCabe et al., 1991), new auction mechanisms (McCabe et al., 1989), the effect on prices of market practices such as, rate filing policies

* Tel.: +34-91-624-9651; fax: +34-91-624-9875.

E-mail address: kujal@eco.uc3m.es (P. Kujal)

${ }^{1}$ Besides testing economic theories for their predictive capabilities. 
(Hong and Plott, 1982), mergers (Davis and Holt, 1994) and effect of list prices and discounts (Davis and Holt, 1998) etc. Experimental work on network industries has focussed on issues such as the structure of ownership of a network, costs, firm concentration etc. in a relatively simple environment. The advantage of using experimental methods in such environments lies in the fact that policy makers can study how changing the market rules can affect outcomes prior to applying the policy change. Such an exercise gives regulators an educated guess (at a much lower cost) about the possible effects of changing market rules. For example, what motivated the Arizona Stock Exchange to adopt the uniform price double auction were the results from a large number of experiments that showed that this mechanism has good efficiency properties ${ }^{2}$.

Another area where experimental methods have been applied is to test the effect of price controls and quotas on market outcomes. Earlier work on price controls in experimental markets has shown that non-binding price controls affect price convergence and price dynamics in both posted-offer and double auction markets. Isaac and Plott (1981) report results of twelve two-sided oral auction markets where they show that the 'focal point' hypothesis, that is whether price floors (ceilings) below (above) the competitive equilibrium will serve as the signaling price, is rejected. Further, they present inconclusive evidence on how price ceilings/controls may in fact bias the price convergence path. Smith and Williams (1981) present further experiments on price ceilings in double auction markets. They report results of sixteen experiments designed to separate between whether price convergence from below/above the competitive equilibrium (CE) when there is a non-binding price ceiling/floor is due to the non-binding price ceiling/floor, or due to the effect of the price ceilings on buyer/seller bargaining strength. They report that the effect on convergence is due to the effect on bargaining strength of market participants. Ceilings induce lower offers by sellers and slightly lower bidding by buyers. Further, they report that the qualitative results of Isaac and Plott carry over to their design, that is, non-binding controls affect market performance and after the removal of the price ceilings there is a discontinuous jump of prices. Further results on price ceilings were presented by Coursey and Smith (1983) in posted-offer markets. They confirm that the qualitative results carry over from the double auction institution. Non-binding price ceilings affect market performance and prices jump discontinuously after the price ceilings are removed in posted-offer markets.

Kujal (1994) conducted experiments where he studied whether non-binding/ binding quantity controls affect market performance in the same way as do price ceilings. That is, whether the qualitative properties observed with quota experiments carry over to experiments with price ceilings or not. He found that after the removal of the controls there is no evidence of the discontinuous jump of prices, neither in the experiments with binding quotas, or in the experiments with

\footnotetext{
${ }^{2}$ Plus the fact that an end-of-the-day uniform price reduces market volatility substantially.
} 
non-binding quotas. Further, in his experiments a surprising property of price convergence was observed. Prices converged from below the competitive ${ }^{3}$ equilibrium. This result contradicted the well established empirical property that in posted-offer markets price convergence is from above the CE. Thus, the asymmetric distribution of quantity restrictions, or quotas themselves affect the price convergence path in the experiments (see Kujal (1992)). Plott (1983) looked at the case of standards in the presence of externalities in oral double auction markets. One can look at Plott's experiments as using market quota kind of restrictions where the total quantity sold by all the sellers is restricted. The standards approach was not as efficient as using tax policy as corrective policies for pollution, but is more efficient than using no policy at all. Using standards, prices showed little or no tendency to converge.

It is easy to see that as price controls put an upper/lower limit on prices they favor either the buyer or the seller. Price ceilings tend to favor buyers as they not only limit the maximum price that the sellers can post, but they also affect the bargaining strength of sellers (Smith and Williams (1981) argue that the downward price in their experiments is due to the effect of price ceilings on bargaining power). On the other hand, price floors would tend to favor sellers if the market provided market power opportunities, or the floor facilitated collusion between the firms.

Similarly, with quantity restrictions the transfer depends upon the specific nature of the quantity restriction and how the quantity rationing is done. Quantity restrictions can be broadly defined under two categories, firm-specific quantity restrictions and market quotas. Firm-specific quantity restrictions limit the amount each firm can sell (thereby limiting its effective capacity). Examples of firmspecific quantity limits were prevalent in planned economies and currently exist for wine imports, production of hops, peanuts and other agricultural products in the U.S. Firm-specific quotas have also been imposed in several farming sectors under the provisions of the Marketing Agreements in the U.S. (Hoffman and Libecap, 1991). Under this scheme cooperatives manage the individual production of its member farmers and the Federal Government limits the interstate flow of these goods (the Federal Government can limit interstate commerce and not intrastate commerce). In this manner an effect similar to firm-specific quotas is achieved. The objective of firm-specific quotas is to transfer income in favor of the producers, as was the case of the citrus industry in the U.S., where firm-specific quantity restrictions have been used to raise and stabilize prices ${ }^{4}$. Market quotas, on the other hand, are imposed on an aggregate of sellers. Examples of market quotas are the Voluntary Export Restrictions that the U.S. and the European Union impose on Japan and Korea on a wide range of goods. Market quotas by their very nature are discriminatory. That is, they limit the sales of a subgroup of sellers only.

\footnotetext{
${ }^{3}$ The issue as to what is appropriate definition of $\mathrm{CE}$ is dealt later.

${ }^{4}$ See Hoffman and Libecap ibid.
} 
However, in this sense they can work as a collusion facilitating device. This, however, depends on the number of firms inside and outside the jurisdiction of the market quota. For the case of two firms, one home and the other foreign, they are equivalent to firm-specific quotas. However, as one increases the number of the firms inside and outside the quota regime the effect is not very clear. For example, several of the Japanese firms bypassed the restriction by investing in plants in the U.S. and in Europe. Moreover, cooperatives may be used to assign individual quantities to sellers even though the quota is meant for the aggregate of the sellers (as was done in the U.S.). The effect of such a kind of allocation is then the same as firm-specific quotas.

A relevant question to ask is, what could be the possible motive behind the imposition of price or quantity controls ${ }^{5}$ ? One can broadly define the cause behind the imposition of a restriction as being due to efficiency or distributive reasons. The motives for imposing a restriction are distributive if for example a price control, or quota, is imposed to favor a certain group of buyers/producers. Under such restrictions the markets need not achieve 100\% efficiency levels. Most restrictions of these kinds are mostly imposed due to political reasons ${ }^{6}$. However, imposing a restriction for efficiency reasons may be motivated by the fact that either restriction, price or quota, results in the same levels of efficiency. Deciding on allocating resources on the basis of prices or quantities within organizations ${ }^{7}$, or planned economies, where distributive objectives are not the motivating factor may be some examples of restrictions motivated by distributive objectives. This then implies that for a quota an equivalent price ceiling, or floor, will be decided by the objectives of the regulator. That is, if the objectives of the planner are distributive then, given a quota, a price control that achieves the same objectives is a floor ${ }^{8}$. However, if the regulator has efficiency objectives then there may not exist a floor that guarantees the same level of efficiency, the only alternative in this case would then be a price ceiling. Of course, the trick would then lie in identifying such a price ceiling.

Till now no attempt has been made to compare the effect of price ceilings and firm-specific quantity restrictions in experimental posted-offer markets. It is of interest for economists to see how these two modes of regulatory control affect market performance. That is, are the two modes equivalent in any sense? Equivalence is not defined in the sense that the two modes are substitute instruments, rather I focus on whether the outcomes associated with the two modes

\footnotetext{
${ }^{5}$ I would like to thank one of the referees for making me think more about this.

${ }^{6}$ The examples on quotas or price floors for agriculture would fall under this category.

${ }^{7}$ See Weitzman (1974).

${ }^{8}$ This holds as it biases rents in favor of the sellers. Though, depending upon the degree of competitiveness of the market, a floor may not achieve the same objectives as does a quota. That is, while a quota allocates quantity among the sellers (it is non-discriminative) a price control may allocate sales on the basis of costs and prices. If asymmetries are present in capacities and costs, then a price control may not distribute the rents in the same way as does a firm-specific quota.
} 
of controls are statistically different, or not. For example, do two modes of controls generate different efficiency outcomes? What effect do they have on the price dynamics (given that in experiments price controls have an effect on prices)? These are relevant questions for any system that plans to use prices and quantities as two modes of regulatory control.

In this paper I study the effect of firm-specific ${ }^{9}$ output limits against price ceilings in experimental posted-offer markets. Firm-specific output limits are chosen as they are the most widely used form of quantity restrictions and many market quotas restrictions eventually end up functioning as firm-specific quotas. Comparison of these two modes of regulation is of interest as they are used as regulatory mechanisms in many economies.

Moreover, it is interesting to see how price dynamics are affected by the two regulatory controls. (This is related to the question raised by Weitzman (1974) where he asks the question why quantities, and not prices, are the preferred modes of control for internal transfers in a firm.) From the experimental evidence it seems that given the quotas sellers take time to 'find' the equilibrium price. However, with a price control it seems much easier to find the profit maximizing quantity. Further, it should be of interest to regulators as to how price and quantity controls affect price dynamics and market efficiency. The success of a policy may in fact depend on these dynamics.

The effect on market efficiencies for firm-specific quotas and price ceilings is also compared. Non-binding quantity restrictions, imposed at the market clearing level, and binding quantity restrictions, imposed at a quantity less than the market clearing amount, are compared to 'equivalent' price ceilings. Only total and seller efficiency levels are compared as simulated buyers are used in the experiments. Given that with human buyers the posted-offer institution favors the sellers, one would expect the seller's share of the surplus to be upwardly biased with passive buyers. In terms of the frequent usage of allocations of jobs by quotas rather than price transfers it is also argued that quotas could be chosen more frequently over prices due to the ease of 'naming' the appropriate quantity over the appropriate price, at least in the short run.

The different efficiency results, for the duration of the restriction, obtained under the two restrictions are explained by examining how firm-specific quantity controls affect the seller search space. Due to the manner in which the controls affect the search space different dynamics are observed in prices, for both price ceilings and quantity controls. It is argued that in market settings the efficiency effects of the two controls may not be the same, especially in the early periods. That is, under quantity controls the sellers have freedom to search in the price space. This is not possible with price ceilings as they impose an upper bound on

\footnotetext{
${ }^{9}$ I study firm-specific restrictions only as the majority of the quantity restrictions are of the firm-specific kind.
} 
prices. Thus, under firm-specific quotas sellers can price themselves out of the market (in the early duration of their search). This results in lower efficiency and output levels under firm-specific quotas than under equivalent price ceilings.

\section{Experimental design}

The experiments use the Plato posted-offer exchange mechanism ${ }^{10}$. In the posted-offer market mechanism sellers post a selling price at the beginning of each trading period. Once the prices have been displayed to all buyers and sellers, buyers then proceed to buy (buyer queue can be set to a random or efficient queue). Once the buyers have made their purchases then the process is repeated for the subsequent period.

The following designs are used for the quota and price control experiments. For both the quota and price control experiments subjects with previous experience ${ }^{11}$ in posted-offer markets were used.

\subsection{Quota experiments}

There are two different experimental designs with binding (excess demand at the $\mathrm{CE}$ ) and non-binding quotas (no excess demand at the CE). The quotas are removed midway, quotas $(\mathrm{Q})$ and no-quotas $(\mathrm{NQ}),{ }^{12}$ in all the experiments. Five experiments are run for each case.

In the experiments the buyers are simulated and are queued randomly. The buyers do not withhold quantity and accept trades at zero 'profit'. This is done as the primary concern was to look at seller behavior in the presence of the price/quantity restrictions. The sellers are not told that the buyers are simulated, nor do the sellers know the capacities or costs of the rival firms.

(i) Quotas at the CE: non-binding quotas (NBQ) (Fig. 1)

There are four buyers and four sellers in the experiment. The surplus is symmetrically distributed about the CE. The sum of the capacities of all the sellers equals thirteen (three sellers with a capacity of three and one with a capacity of four). This does not alter the competitive price ${ }^{13}$ and quantity outcome from the price control experiments. Note, that $12-13$ units can be traded.

\footnotetext{
${ }^{10}$ For detailed instructions in the posted offer institution see Ketcham et al. (1984).

${ }^{11}$ Each subject had been in posted offer experiments two times in the past.

${ }^{12}$ The primary concern was to study the effect of the removal of the quantity restrictions. As a result no NQ/Q experiments were conducted.

${ }^{13}$ The competitive price is defined as the price where total surplus is maximized. That is, given the random queue there exist possibilities for over and undertrading. However, if this occurs higher cost units will be sold and thus total surplus will not be maximized.
} 


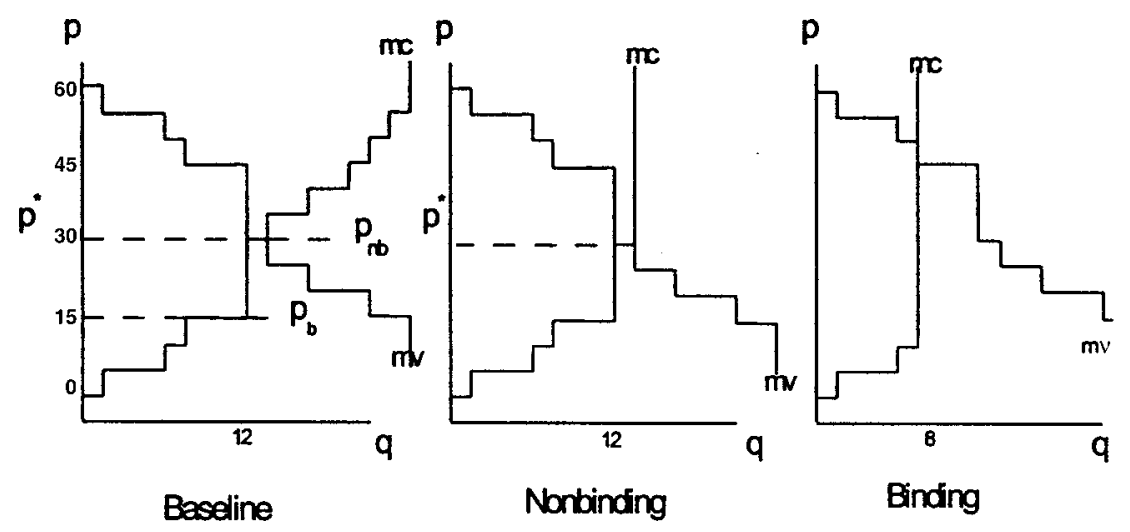

Fig. 1. Marginal cost and marginal valuations.

(ii) Quotas below the CE: binding quotas (BQ) (Fig. 1)

There are four buyers and four sellers in this design. The sum of the sellers capacities equals eight (each seller has a capacity of two). The MC curve overlaps the MV curve in a five cent range. This is $15-20$ cents above the CE in the NBQ design.

The subjects receive a special announcement that during each trading period quantity controls will be in effect when appropriate. If any seller attempts to violate their quota restriction, that is, sell more units than their (maximum) production quota, it results in the rejection of the seller's offer until the output constraint (quota) is satisfied. Subjects are also told that their capacity is determined by a central authority. This announcement is made to all the subjects. They are also given individual announcements that state their capacities and the changes in their capacities in the middle of the experiment ${ }^{14}$. This announcement is given to all the subjects prior to the beginning of period 11 .

Each experiment consists of twenty trading periods. The trading periods are split into groups of ten each. For the Q/NQ experiments quantity controls are imposed for the first ten periods, and then removed for the remaining ten periods. With non-binding quotas each individual firm can sell at most three units each (the same as at the CE). However, seller 1 has an additional unit at the CE. Note that the competitive outcome of 12 (and not 13) is attained as no commissions are given for the units traded. With the binding quotas each firm can sell at most two units. Note that everyone knows that the individual capacities have been changed, however, individual capacity changes are private information.

\footnotetext{
${ }^{14}$ For details of the quota experiments see Kujal (1994).
} 


\subsection{Price control experiments}

To keep the results of the price control experiments comparable to the quantity controls experiments, simulated buyers are used. As in the quantity controls experiments the buyers do not withhold and accept trades at zero profits. As in the quota experiments, information on capacity, the size of the changes in capacity and cost is private. Sellers are not told that the buyers are simulated as the intent was to focus on seller behavior. The sellers are told that price ceilings are in effect. They are given the maximum price for which they can sell the units. We run experiments with binding $\left(p_{b}<p^{*}\right)$ and non-binding price ceilings $\left(p_{n b}=p^{*}\right)$ (Fig. 1). The price ceilings are set such that they are consistent with the quantity controls (as we have horizontal overlap in the quantity space we get unique prices). Note, that a price of $p^{*}$ also ensures $100 \%$ efficiency, any other price results in out of equilibrium units being traded and hence lower efficiency levels. Halfway through the experiments the price ceilings are removed. Three experiments are run for the non-binding price control experiments and two for the binding control experiments ${ }^{15}$.

\subsection{Market power and the competitive price}

A competitive price is defined as the price where total surplus is maximized and all the firms take the price as given. At price $p^{*}$ total surplus is maximized, any price less than or equal to $p^{*}$ some out of equilibrium units are sold and thus $100 \%$ efficiency is not achieved. Further, for $100 \%$ efficiency to be achieved above this price firms need to behave in strategic manner, i.e., agree to restrict output. Looking at Fig. 1 it is seen that in the baseline design the competitive price outcome is not a Nash equilibrium. Assuming all firms charge a price of 30 (Fig. 1 , Table 1) it is clear that any seller can unilaterally increase earnings by charging a price of 45 . If seller 1 does not withhold her marginal 30 cent unit the deviating seller gains 30 cents by selling 2 units which is greater than the 15 cents lost if all three units were to be sold at the competitive price ${ }^{16}$.

Thus, a price of 30 charged by all sellers is not a Nash equilibrium. Given that there does not exist a unique equilibrium in price (output) corresponding to a unique output (price) I define the competitive price in the standard manner. It is the price where the firms take the price as given and this price maximizes total surplus. In our design this is observed at the cross-over of the MV-MC curve. In this sense this implies that firms behave in a non-strategic manner ${ }^{17}$. The price that

\footnotetext{
${ }^{15}$ Fewer price ceiling experiments were run due to budgetary constraints.

${ }^{16}$ One of the anonymous referees suggested this simpler version of showing why the competitive price is not a Nash equilibrium.

${ }^{17}$ There are other price configurations where total welfare is $100 \%$ and sellers withhold output (one of the referees pointed this out). However, this entails strategic behavior on the part of the sellers, or non-unique prices.
} 
Table 1

Marginal cost and marginal valuations

\begin{tabular}{llllll}
\hline & Unit 1 & Unit 2 & Unit 3 & Unit 4 & Unit 5 \\
\hline Buyer 1 & 60 & 55 & 45 & 20 & 20 \\
Buyer 2 & 55 & 50 & 45 & 25 & 15 \\
Buyer 3 & 55 & 50 & 45 & 25 & 15 \\
Buyer 4 & 60 & 55 & 45 & 30 & 20 \\
Seller 1 & 00 & 05 & 15 & 30 & 40 \\
Seller 2 & 05 & 10 & 15 & 35 & 45 \\
Seller 3 & 00 & 05 & 15 & 35 & 55 \\
Seller 4 & 05 & 10 & 15 & 40 & 50 \\
\hline
\end{tabular}

guarantees $100 \%$ (output of $12 / 13$ ) level of efficiency is 30 . Also note, that any price less than 30 only decreases the efficiency for the same, or a lesser, amount of the good.

Educated guesses on prices can be made to show the approximate price equilibrium in the experiments. This is useful, as it gives us a price prediction for the experiments. It is seen that if a seller prices at 45 the minimum amount it sells is 2 units. The gain (30) dominates the loss on the unsold unit (15). Now assume that everyone prices at 45 , however, at this price some sellers gain by lowering the price and selling 4 units. In fact all sellers gain by lowering their price and selling additional units. What is important is to determine up to what price each seller is willing to lower its price such that the net gain from undercutting and selling more is positive. This can be done individually for all the sellers. Seller 4 only finds it profitable to undercut till 40 and not below. The maximum it gains from undercutting is 56, from pricing at 44 and selling 4 . Now, sellers 2 and 3 can price at 39 , sell 4 units and gain 36 cents (which is greater than the 30 gained from selling 2 units). The only seller that will undercut them at this price is firm 1 that has the only available extra unit at 30 . Seller 4 will never undercut below 40 cents and sellers 2 and 3 never undercut below 37.5 cents (with a gain of 7.5 cents on each unit, selling 4, it makes them indifferent between pricing at 45 and pricing at 37.5). Now, all we need to do is to see if seller 1 wants to price below 37.5. At any price below 37.5 , selling 4 units, seller 1 earns less $(7 \times 4=28)$ than the 30 cents it earns at a price of 45 . Hence, we know that no seller prices below 38 cents (as prices in decimals are not admitted). This simple exercise gives us an idea that the approximate range of equilibrium prices lies in $[38,45]$.

\section{Experimental results}

Results are compared for the effect on contract realization, surplus realization, and price convergence. Aggregate sales of $12 / 13$ are taken to imply that $100 \%$ of the units are sold. Note that even if 12 units are sold that does not imply that $100 \%$ efficiency level is achieved. With the random queue it is possible that some sellers 
may in fact sell high cost units. Thus, especially in the earlier periods where such trades are possible due to large price dispersion, there does not exist a one-one relationship between total contracts and total efficiency. Thus, we study both total contracts realization and total efficiency level in the experiments.

The two sample Wilcoxon rank-sum test is used for the statistical tests. The test is performed on disaggregated data from the experiments. Observations from all the experiments for the first half of the experiments (periods 1-10) are tested against observation from the ten periods in the second half (periods 11-20).

\subsection{Non-binding controls}

\subsubsection{Contract realization (Fig. 2a)}

With non-binding quotas (henceforth, nbq) the contracts realized (relative to the $\mathrm{CE})$ are significantly lower than in the price control experiments (henceforth, pc). In the nbq experiments the contracts converge from and stay well below the contracts realized in the pc experiments till the eleventh period. The Wilcoxon ${ }^{18}$ rank-sum test results are presented in Table $2^{20}$. All tests are conducted separately for the periods in which controls are (not) in effect nbq.

An interesting result observed is that in the first ten periods the nbq and pc experiments are significantly different (Fig. 2a). Given the same experimental design we see that quotas adversely affect market performance relative to price ceilings. This result is important because it shows that the observed dynamics under price and quantity controls are not similar.

Also, in Table 2 we see that contracts realized are not significantly different for the two experiments. Another interesting observation is that in the second part the pair nbq-pc is not significantly different. However, the pair is significantly different in the first part. Clearly, quantity controls affect market outcomes (negatively) in the short run.

Table 2

\begin{tabular}{lrl}
\hline & z-Stat $^{19}$ & Significance \\
\hline nbq vs. pc (periods 1-10) & 6.438 & 0.00 \\
nbq vs. pc (periods 11-20) & -0.331 & 0.74 \\
\hline
\end{tabular}

${ }^{18}$ Due to the time dependence of prices and efficiencies these results should be viewed as a rough indicator.

${ }^{19}$ Non-parametric tests are used due to the small sample size.

${ }^{20}$ It should be pointed out that in this paper the interest is on the effect of the price ceiling and quantity control on the market in the short run only. In a static environment it is clear that, in the long run, with a sufficiently long experiment prices will converge. In our experiments it can be seen that by the end of the 20th period convergence close to the joint profit maximum is obtained. 


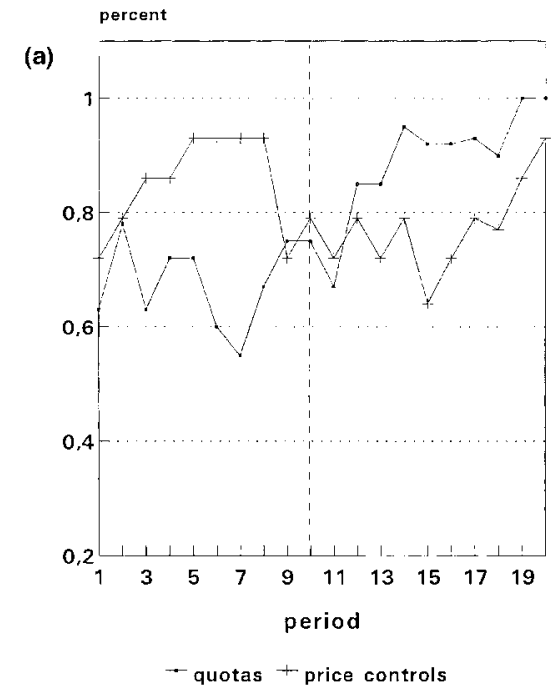

Expressed as a percentage of the CE/controls removed period $\uparrow 1$

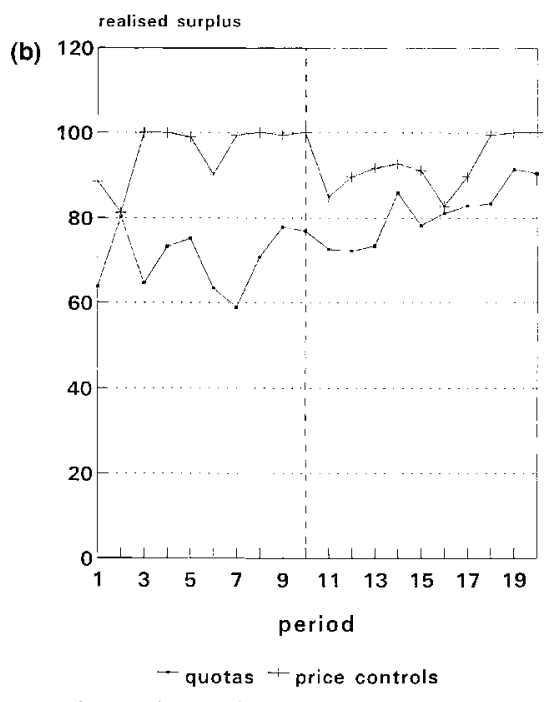

quotas-price controls removed period $\mathbf{1 1 .}$

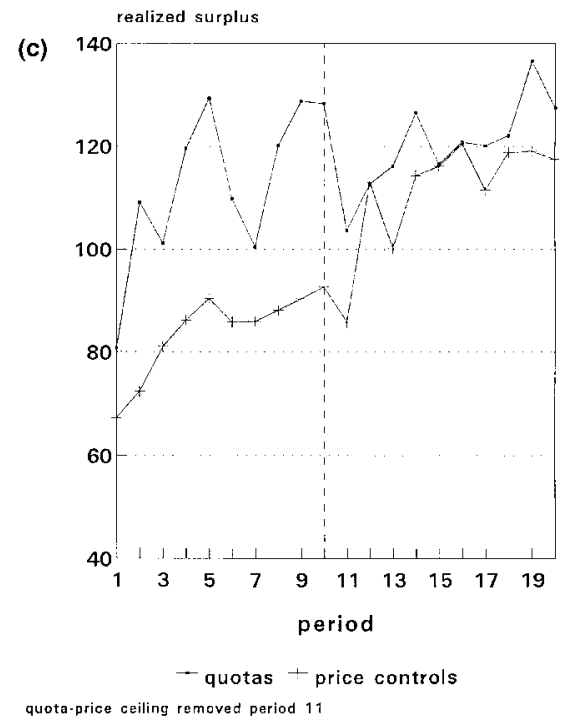

Fig. 2. Non-binding controls. (a) Percent contracts realized. (b) Total realized surplus. (c) Sellers realized surplus.

\subsubsection{Surplus realization (Fig. 2b)}

The nbq experiments exhibit lower surplus realization in the early periods relative to the pc experiments. However, surplus realization never converges to 100\%. Paired rank-sum Wilcoxon test results are reported in Table 3. 


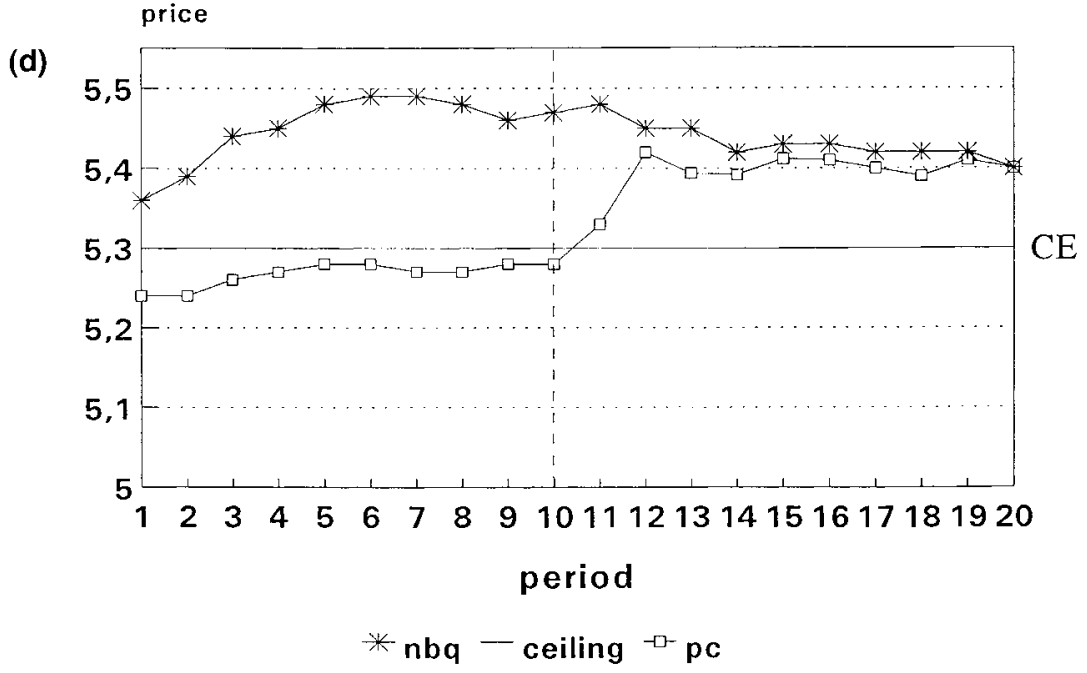

quota-price ceiling removed period 11 .

Fig. 2. (Cont.) Non-binding controls. (d) Average contracted prices. (e) Average posted prices.

These results show that surplus realization under quotas is significantly different than surplus realization under price ceilings in the first ten periods. It is clear that in the early periods surplus realization in the quota experiments is well below the 
Table 3

\begin{tabular}{lll}
\hline & z-Stat & Significance \\
\hline nbq vs. pc (periods 1-10) & 6.01 & 0.00 \\
nbq vs. pc (periods 11-20) & 0.056 & 0.955 \\
\hline
\end{tabular}

price control experiments (Fig. 2b). Surplus realization in the second half of the experiments is not significantly different between the nbq and pc experiments.

Two important results are observed in the non-binding control experiments. First, contract (and surplus) realization in the nbq experiments is lower than the price control experiments. Quantity controls affect market outcomes adversely at least in the early phase of their implementation. Second, we have a reaffirmation of the earlier experimental results done with price controls, that is, non-binding controls affect market performance. This is observed not only with non-binding price controls but also with non-binding quantity controls.

In the early stages of the experiments surplus and contract realization in the quantity control experiments is lower than under the price control experiments. One reason could be that the two controls impose different search characteristics on the economic agents in the institution. With quantity restrictions there is greater freedom of search in the price space. As a result, the sellers tend to price themselves out of the market. On the other hand price ceilings restrict search in the price space, thus they do not allow the sellers to price themselves out of the market. This could be an explanation for the lower surplus, and contract realization, in the quota experiments.

\subsubsection{Prices (Fig. 2c,d)}

From the figure it is clear that prices for both the quantity and price ceilings converge close to the joint profit maximizing price as soon as the price ceilings are removed. Also, after the removal of the (price) ceilings prices jump. This is along the lines of the earlier price control experiments.

\subsection{Binding controls $(b q)$}

\subsubsection{Contract realization (Fig. 3a)}

A result consistent with the nbq experiments is that the contracts realized in experiments with quantity restrictions start well below the pc experiments. However, after the initial drop contracts gradually increase. The Wilcoxon ranksum test results are reported in Table 4.

These results are consistent with the non-binding control experiments. Quantity Table 4

\begin{tabular}{lll}
\hline & z-Stat & Significance \\
\hline bq vs. pc (periods 1-10) & 6.88 & 0.00 \\
bq vs. pc (periods 11-20) & 1.49 & 0.137 \\
\hline
\end{tabular}



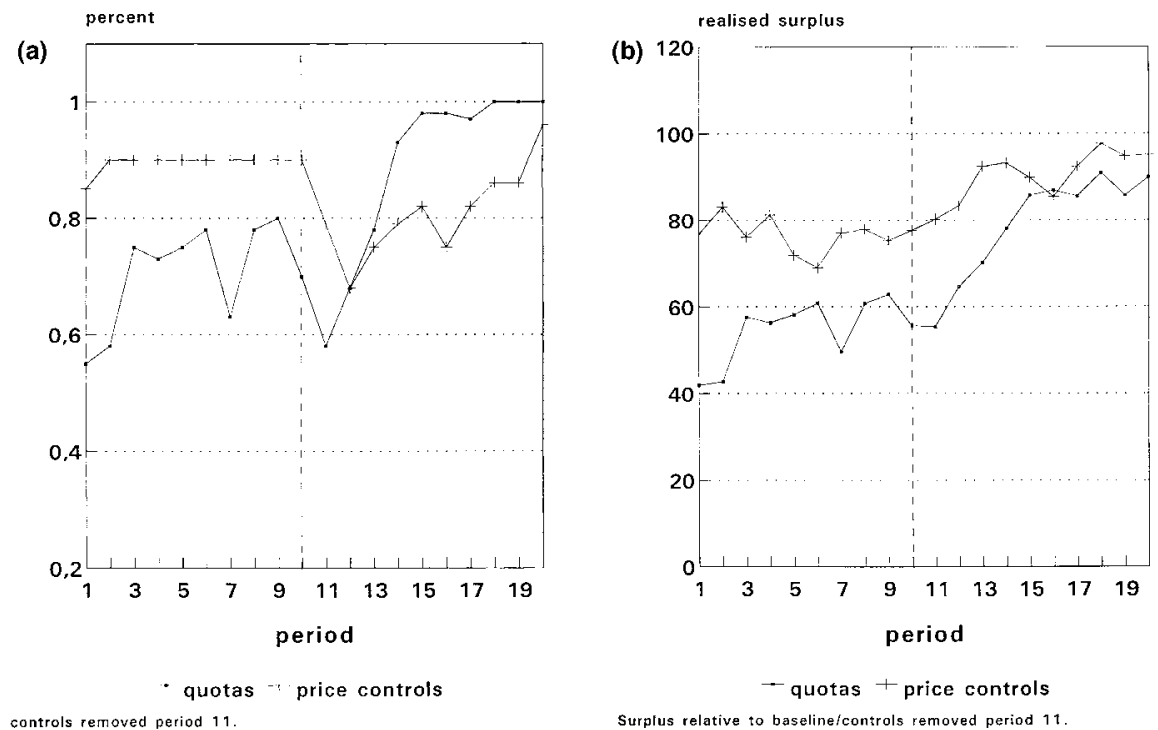

controls removed period 11

Surpitus relative to baseline/controls removed period 11 .

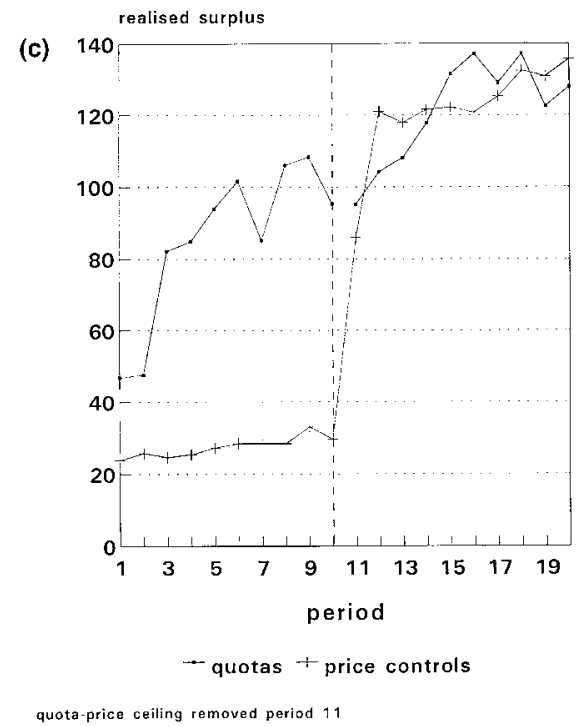

Fig. 3. Binding controls. (a) Percent contracts realized. (b) Total realized surplus. (c) Sellers realized surplus.

restrictions affect market performance adversely, especially in the early phases of the experiment. In the early periods contract realization in the bq experiments stays well below contract realization in the price control experiments (Fig. 3a). Also, the 

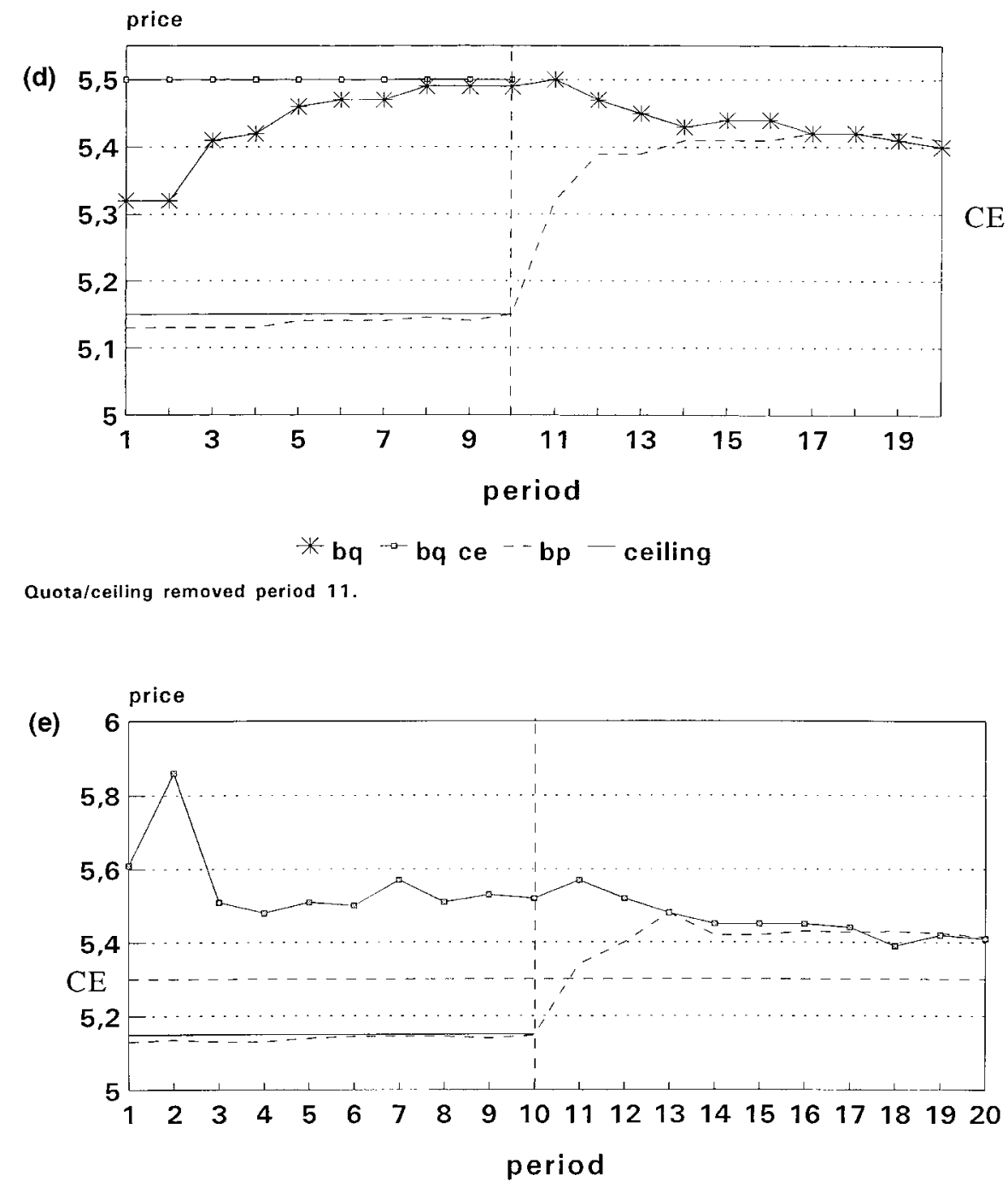

- ceiling ${ }^{-\rightarrow}$ quotas ${ }^{--}$price ceiling

controls removed period 11

Fig. 3. (Cont.) Binding controls. (d) Average contracted prices. (e) Average posted prices.

manner in which the controls affect market outcomes is consistent with what was observed in the non-binding control experiments. That is, in the second half contract realization is not significantly different in the price control or quantity control experiments. 
Table 5

\begin{tabular}{lll}
\hline & z-Stat & Significance \\
\hline bq vs. pc (period 1-10) & 3.05 & 0.002 \\
bq vs. pc (period 11-20) & 1.312 & 0.189 \\
\hline
\end{tabular}

\subsubsection{Surplus realization (Fig. 3b)}

Although surplus realized in the bq/pc experiments starts low, surplus realization in the binding quota experiments is well below surplus realization in the price control experiments for many periods. Total efficiency in the pc experiments starts at $62.50 \%$, which is greater than in the bq $(41.94 \%)$ experiments. This result can once more be explained by the manner in which search characteristics are affected by the two controls.

The Wilcoxon rank-sum test indicates that for the first part of the experiment surplus realization between the price control and quota experiments is significantly different. In the second half of the experiments (Table 5) the results are similar to that obtained in the non-binding control experiments. That is, efficiency in the quota experiments is not significantly different than the efficiency in the price control experiments. Regularity is observed in the manner in which quantity restrictions and price outcomes, non-binding or binding, affect market outcomes.

\subsubsection{Prices (Fig. 3c,d)}

Price behavior is similar to what was observed in the non-binding quota experiments. After the removal of the price control a jump is observed in prices. This jump is relatively more in the binding control experiments as the price control was 15 cents below the CE. However, towards the end of the experiments the prices converge. Prices do start from slightly below the binding price ceiling. Given the fact that the binding price ceiling did not leave a substantial profit margin it is striking to see that prices still start, even though slightly, from below the ceiling.

The earlier explanation that this may be due to the fact that the sellers had earlier experience in posted-offer markets and given that he/she had learned that if they post a high price they may not sell (Coursey and Smith (1983), p. 220) does not seem satisfactory. That is, keeping this explanation as the valid one, how do we explain the jump in prices after the price ceilings are removed? Given this premise we should see a gradual and not sudden increase in prices (assuming this aversion to not selling on the part of sellers. ${ }^{21}$ Note, this convergence property is similar to what was observed in Kujal (1994) where with binding quotas sellers price below even the 'competitive-market' equilibrium. It seems that the mere imposition of a restriction alters sellers' expectations on the prices they can post.

\footnotetext{
${ }^{21}$ At this stage Coursey and Smith argue that the jump can be explained by (sic) 'pent-up' or accumulated unsatisfied demand. However, these two explanations, low prices due to the knowledge that high prices will not sell and high prices due to (pent-up) demand, are not consistent.
} 
Why and how this occurs needs to be investigated further given the scant experimental evidence on this issue.

\section{Conclusion}

We see that quantity restrictions, binding or non-binding, have adverse implications on market performance relative to price ceilings. The two controls 'censor' information in different ways in market environments. Price ceilings and quantity controls, binding or non-binding, place artificial bounds on the search space. Price ceilings let the market participants search in the quantity space while limiting the price search space. (Note, in a posted-offer market price choice determines the maximum quantity a seller can choose. Thus, price ceilings are more restrictive in a posted-offer market.) Similarly, quantity restrictions do not affect the price search space but limit the quantity search space. Allowing for freedom of search in the price space we observe sellers pricing themselves out of the market in the early stages of the experiment. This results in lower contract and efficiency realization in the earlier stages of the experiments. Our results confirm that quantity controls affect market performance adversely relative to price ceilings. This is reflected by lower contract and total surplus realization in the early stages of all the experiments.

Secondly, these results provide an indication of why quantity restrictions are chosen more frequently over price ceilings. In this paper it is seen that for the sellers, given the quantity, finding the 'right' price in the short run is not an easy task. It is clear from the experimental results that with quotas, where sellers search for prices, efficiency and output are lower. Thus, if finding the right price involves costs in the short run firms may resort to using quantity restrictions which are easier to 'name'. As a result, if the short run costs are high, it is easy to see why transfer of jobs in organizations may be done by the use of quantity restrictions over prices. This may explain the question raised by Weitzman, that is, why transfers using quantity controls are used more frequently than prices.

These results are important as they point out that the manner in which the market controls affect price search space determines the welfare implications in a market setting, and that quantity controls adversely affect market outcomes in the short run relative to price ceilings. If attaining lower prices is the objective, price ceilings do it best. However, if resources need to be rationed, quantity controls are the available recourse.

\section{Acknowledgements}

Thanks go to Stan Reynolds, Mark Isaac, Tim Cason, Klaus Desmet, two anonymous referees for detailed comments and the editor. Financial support for the experiments was provided by the Economic Science Laboratory, University of 


\section{Arizona. The author acknowledges financial support from DGICYT grant \#PB95- 287. All remaining errors are of course the author's.}

\section{References}

Coursey, D.L., Smith, V.L., 1983. Price controls in a posted-offer market. American Economic Review 73 (1), 218-221.

Davis, D., Holt, C., 1994. Market Power and Mergers in Laboratory Markets with Posted Prices. Rand Journal of Economics 25 (3), 467-487.

Davis, D., Holt, C., 1998. Conspiracies and secret discounts in laboratory markets. Economic Journal 108 (448), 736-756.

Hoffman, E., Libecap, G.D., 1991. Institutional choice and the development of U.S. agricultural policies in the 1920's. The Journal of Economic History 51, 397-411.

Hong, J.T., Plott, C.R., 1982. Rate filing policies for inland water transportation: an experimental approach? Bell Journal of Economics 13 (1), 1-19.

Isaac, R.M., Plott, C.R., 1981. Price controls and behavior of auction markets: an experimental examination. American Economic Review 71, 449-459.

Ketcham, J., Smith, V.L., Williams, A.W., 1984. A comparison of posted-offer and double-auction pricing institutions. Review of Economic Studies 167, 595-614.

Kujal, P., 1992. Asymmetric surplus distribution and the price convergence path in posted-offer market. Economic Letters 39, 33-36.

Kujal, P., 1994. Firm-specific output limits in a posted-offer market: distributive and efficiency effects. Journal of Economic Behavior and Organization 25, 257-269.

McCabe, K., Rassenti, S., Smith, V.L., 1989. Designing 'smart' computer assisted markets in an experimental auction for gas networks. European Journal of Political Economy 5, 259-283.

McCabe, K., Rassenti, S., Smith, V.L., 1991. Experimental research on deregulated markets for natural gas pipeline and electric power transmission networks? Research in Law and Economics 13, $161-189$.

Plott, C., 1983. Externalities and corrective policies in experimental markets. The Economic Journal 93, $106-127$.

Rassenti, S., Smith, V.L., Bulfin, R.L., 1982. A combinational auction mechanism for airport time slot allocation. Bell Journal of Economics 13 (2), 402-417.

Smith, V.L., Williams, A.W., 1981. On non-binding price controls in a competitive market. American Economic Review, June, 467-474.

Weitzman, M.L., 1974. Prices vs. quantities. Review of Economic Studies, October, 477-491. 